\title{
EFEITO DA SEDIMENTAÇÃO SOBRE A DISTRIBUIÇÃO DE Batillipes pennaki Marcus, (1946) EM ZONA TROPICAL TÍPICA : RESTINGA DO PAIVA, PERNAMBUCO, BRASIL.
}

Francisco José VICTOR-CASTRO Departamento de Oceanografia ( PPGO) - UFPE. CNPq. Verônica FONSÊCA-GENEVOIS Departamento de Zoologia, UFPE. CNPq.

Luiz LIRA

Departamento de Pesca, UFRPE.

Clélia Márcia Cavalcanti DA ROCHA

Departamento de Biologia - UFRPE Departamento de Oceanografia (PPGO) - UFPE

\section{RESUMO}

Com o objetivo de estudar os impactos dos processos morfodinâmicos associados às características eco-morfológicas de Batillipes pennaki Marcus, (1946), foram realizadas coletas de meiofauna, levantamentos topográficos e análises granulométricas quinzenalmente durante 6 meses (junho a novembro/1995) em 2 estações mediolitorânea na Restinga do Paiva-PE. Os sedimentos revelaram uma alternância de areias quartzosas de média a fina e de processos de erosão e deposição. Na estação I Batillipes pennaki dominou em $28 \%$ a comunidade e na estação II, atingiu a densidade máxima da restinga (11179.2 ind. $10 \mathrm{~cm}^{2}$ ) dominando em $50 \%$.Os processos sedimentológicos influenciam diretamente na distribuição de $B$. pennaki.

Palavras-chave: Meiofauna, Tardigrada, Batillipes pennaki, Morfodinâmico, Banco de areia

\section{ABSTRACT \\ The Effects of Morphodynamic Processes on Batillipes pennaki Marcus (1946) Abundance and Distribution in Tropical Regions: The Paiva Sandbank, Pernambuco, Brazil.}

The effects of morphodynamic processes on Batillipes pennaki Marcus (1946) abundance and distribution were analyzed in two intertidal stations at Paiva sandbank. The slope of profile and sediment parameters were measured. Five meiofaunal samples were collected fortnightly, from June to November 1995, at mid tide level with a core of $5 \mathrm{~cm}^{2}$ and a mesh of $0,044 \mathrm{~mm}$. The sediment was composed by medium to fine sands. Depositional processes occurred in the rainy season and erosional processes in the dry season in Station I. B. pennaki was more 
abundant in Station II with $50 \%$ of number of individuals and a maxima density of 11179.2 ind. $10 \mathrm{~cm}^{2}$. Sedimentologic processes influences directly on the specie distribution.

Key-words: Meiofauna, Tardigrada, Batillipes pennaki, Morphodynamic, Sandbank.

\section{INTRODUÇÃO}

A Meiofauna é integrada pelo conjunto dos metazoários aquáticos de dimensões reduzidas $(0,045 \mu \mathrm{m}$ a $0.5 \mathrm{~mm})$ que habitam os interstícios sedimentares ou que mantêm estreitas relações com o fundo móvel dos ambientes aquáticos, vivendo na interfácie água / sedimento (Renaud-Mornant et al., 1984). Bentes et al. (1997) afirmam que os processos dinâmicos das praias definem a distribuição quali-quantitativa das comunidades bentônicas, devido à preferência destes organismos por determinados habitats, condicionados à geoquímica e à granulometria dos sedimentos, e estes, por sua vez, se definem pelas alterações advindas do hidrodinamismo. Santos (1999) apresenta uma síntese sobre os dados de ecologia descritiva da meiofauna brasileira e confirma que o efeito do ambiente e dos sedimentos sobre a densidade média da meiofauna não são significativos. Demonstra, no entanto, que há correlação positiva significa tiva entre $\mathrm{o}$ grupo dominante e a fração dominante dos sedimentos.

$\mathrm{O}$ estudo das modificações morfológicas que ocorrem em um perfil transversal de uma praia, sendo este relacionado com os processos de acresção ou engordamento e erosão, tem se tornado um importante instrumento para projetos de engenharia costeira, para identificação de tendências de erosão ou progradação da linha de costa e suas consequentes implicações no gerenciamento costeiro e nas avaliações de impactos (Bentes et al, 1997). A nível biológico a dinâmica geomorfológica de ambientes praiais atua diretamente na composição e distribuição da meiofauna, sobretudo quanto à dispersão e concentração dos organismos componentes. Aponta Giere (1993) as várias maneiras pelas quais a meiofauna se dispersa/concentra nos sedimentos praiais: por erosão/suspensão, por emergência/suspensão ou por transporte tipo balsa. Afirma, ainda, que os mecanismos de erosão/ suspensão são os mais relevantes em área de maior hidrodinamismo.

Os Tardigrada possuem garras ou dedos dotados de unhas (Ramazotti,1983) que facilitam a dispersão por agregação nos sedimentos. Dentre os fatores ecológicos que condicionam a presença 
dos Tardigrada nos diversos ambientes marinhos, salientam-se as características granulométricas dos sedimentos, a goemorfologia ( Renaud - Debyser, 1963 ; Renaud - Debyser e Salvat , 1963; Pollock, 1970 ), correntes de marés (Renaud - Mornant et al. 1984) e variações climáticas sazonais (Ramazoti, op.cit.). Batillipes pennaki, por possuir peculiar estrutura dos seus dedos terminados em ventosas são perfeitamente adaptados à vida instersticial (Grimaldi De Zio et al, 1983), sendo considerado por Renaud-Mornant e Polock ( 1971) uma espécie consmopolita de larga distribuição geográfica.

Os processos sedimentológicos da Restinga do Paiva, no que se refere à sedimentação do perfil praial associados às características ecomorfológicas de $B$. pennaki permitiram levantar a hipótese de que a densidade da espécie é dependente da dinâmica sedimentar.

\section{MATERIAL E MÉTODOS \\ Descrição da Área}

A faixa sul da Região Metropolitana do Recife é caracterizada pela presença de grandes planícies de cordões litorâneos geradas durante o quaternário, as quais podem formar, atualmente, extensas praias retas, enseadas, ou ainda, pontais arenosos como a Restinga do Paiva (Medeiros, 1996), localizada na desembocadura do estuário dos rios

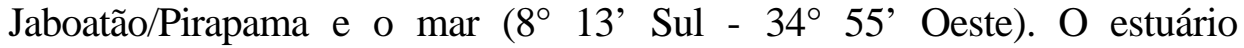
encontra-se nos limites dos municípios do Cabo e de Jaboatão dos Guararapes, nas proximidades de Pontezinha e Ponte dos Carvalhos (Cabo-PE) a $20 \mathrm{Km}$ ao sul da cidade do Recife e ocupa cerca de 1284 ha (Fidem, 1987). Apresenta-se em forma de $\mathrm{S}$ alongado, com largura variando de 200 a $250 \mathrm{~m}$ e comprimento, em linha reta, com cerca de $2.500 \mathrm{~m}$ (LGGM, 1997).

A área se apresenta como uma extensa planície costeira, situada entre o mar e as elevações do Grupo Barreiras, formada por sedimentação flúvio-marinha recente, a qual continua a se processar atualmente, aí ocorrendo alguns fatores essenciais que contribuem para o desenvolvimento de uma restinga, tais como abundância de sedimentos transportados pelos rios, formando bancos de areia que afloram durante as baixa-marés e a ação das ondas (Carneiro \& Coelho, 1960; Carvalho, 1978 apud Couto, 1988).

O ciclo pluvial revela um período de verão ou estiagem (dezembro à abril) e outro chuvoso ou de inverno (maio à novembro), 
característicos de regimes climáticos de latitudes intertropicais. As temperaturas médias anuais variam entre a mínima de $22^{\circ} \mathrm{C}$ e a máxima de $30^{\circ} \mathrm{C}$. A costa de Pernambuco é do tipo meso-maré, dominada por ondas e sob a ação constante dos ventos alísios vindos principalmente de E-SE, no período de abril a setembro, e de N-NE, quando sopram de outubro a março. A maior intensidade ocorre nos meses de agosto e setembro e os ventos alísios de ESE predominam a maior parte do ano (LGGM, 1997).

\section{Descrição do Problema}

As restingas, quando localizadas nas desembocaduras dos estuários, à exemplo da do Paiva (situada no estuário dos rios Jaboatão/Pirapama, litoral sul de Pernambuco), normalmente, são regiões sensíveis, que reagem à ação de vários fatores naturais e antrópicos. As alterações que ocorrem na foz desses cursos d'água ao longo do tempo fazem com que essas desembocaduras mudem de posição, transformando esta região em áreas bastante complexas, sustentadas por contínuas modificações. A direção e intensidade dos ventos que geram as correntes, consequentemente deslocam as areias de praias e das fozes dos rios. Esses movimentos de areias fazem com que as restingas cresçam na direção da deriva.

Em função do estrangulamento de uma das saídas do estuário do rio Jaboatão/Pirapama, possivelmente devido à sedimentação proveniente da deriva litorânea preferencialmente no sentido Sul-Norte (Lira, 1994), os processos erosivos foram se agravando dentro do corpo estuarino. Tais aspectos, obrigavam construções de estruturas rígidas para minimizar a erosão. Os impactos causados com a construção desses espigões, os aterros na margem esquerda do estuário dos rios Jaboatão/Pirapama e o crescimento da restinga do Paiva, aumentaram a velocidade de suas águas, formando um molhe hidráulico perpendicular ao sentido da deriva litorânea, impedindo o transporte das areias oriundas da praia do Paiva para a praia de Barra de Jangadas (Lira, op cit).

Os problemas referidos acima, submeteram a cobertura sedimentar da restinga a um intenso processo morfodinâmico podendo, consequentemente, influenciar na estrutura da comunidade meiofaunística, sobretudo quanto aos organismos que se dispersam agregados aos grãos, como é o caso de $B$. pennaki. 


\section{Estratégias de Trabalho}

As coletas foram efetuadas quinzenalmente durante 6 meses (junho a novembro de 1995) na Restinga do Paiva, no período de maior e menor pluviosidade em 2 estações ao longo da foz do estuário do Rio Jaboatão/Pirapama.

A estação I localiza-se na área onde ocorre um grande estreitamento da calha do rio em lado oposto a um dique de pedra, início da desembocadora do estuário ( $8^{\circ} 13$ ' 34" Sul - 34 $55^{\circ}$ ' 33" Oeste). A estação II ( $8^{\circ} 13^{\prime} 35^{\prime}$ ' Sul - 34 $4^{\circ} 55^{\prime} 33^{\prime \prime}$ Oeste) localiza-se na porção mais externa de influência marinha.

Para a extração da meiofauna utilizou-se tubo de PVC de $5 \mathrm{~cm}$ de área interna, inserido a profundidade de $10 \mathrm{~cm}$. Em um quadrado imaginário de $1 \mathrm{~m}$. $\mathrm{x} 1 \mathrm{~m}$., tomou-se 5 réplicas sempre no médio litoral e na maré baixa, em um ponto aleatório do transecto fixo determinado nas duas estações.

Nas estações foram realizados perfis de praia com auxílio de nível de luneta e mira falante, resultando em levantamentos topográficos da face da praia, também a cada quinze dias nas marés baixas. As leituras foram realizadas desde o supralitoral em um ponto fixo até a face da praia onde fosse possível avançar para obter a leitura.

Aproximadamente $100 \mathrm{~g}$ de sedimentos das estações referentes ao médio litoral foram coletados superficialmente para caracterização das frações granulométricas.

Utilizando a metodologia combinada de Boisseau \& Renaud (1955) e Elmgren (1966), as amostras de bio-sedimentos foram lavadas, elutriadas em becker e passadas entre peneiras de aberturas de malhas de $\mathrm{O}, 5 \mathrm{~mm}$ e $0, \mathrm{O} 44 \mathrm{~mm}$. O material retido foi colocado em placa de Petri para centrifugação manual, sendo o sobrenadante vertido em placas de Dolffus prospectada em seus 200 quadrados, sob lupa binocular para identificação dos meiobentontes a nível de grandes grupos zoológicos.

A análise granulométrica foi realizada com o objetivo de determinar o diâmetro médio dos grãos. Para tal, o material coletado sofreu um processo inicialmente de secagem a temperatura ambiente, sendo posteriormente levado a uma estufa com temperatura em torno de $90^{\circ} \mathrm{C}$ para evitar a aglutinação de grãos ou alteração de peso decorrente da umidade. Foram utilizadas 6 peneiras, com intervalo de $1 \varnothing(1 \mathrm{~mm}$ a $0.062 \mathrm{~mm}$ ). Depois de seco, pesou-se a fração maior que $2 \mathrm{~mm}$ e o material retido na peneira de $0.062 \mathrm{~mm}$ foi submetido ao processo de 
peneiramento através de agitação em uma máquina "rot-up" por um período de 15 minutos para posterior pesagem.

O peso do material fino que foi desprezado foi obtido através da soma dos pesos de cada fração subtraindo-se do peso da amostra total.

Os dados obtidos foram analisados utilizando programa Angra (versão 1.3 - Analisador granulométrico), com fornecimento dos parâmetros texturiais, análises estatísticas e interpretação granulométrica segundo Falk e Ward (1957).

Com os dados de distância e cota relativos ao perfil de praia foram traçados os perfis plotados através de programa de computador, excel versão 7.0 para Windows 95 .

Empregou-se análises de correlação de Spearman e de regressão múltipla sobre a variação de densidade dos Tardigrada. Ainda utilizou-se o teste de Kruskal-Wallis, para verificar se as amostras pertenciam à mesma população estatística.

\section{RESULTADOS}

$\mathrm{O}$ período chuvoso caracterizou-se nos meses de junho à agosto, com uma precipitação total de 792,2 mm e o período seco entre setembro à novembro com uma precipatação total de $0,1 \mathrm{~mm}$.( Tab. 1).

Tabela 1 - Precipitação pluviométrica $(\mathrm{mm})$ total nos meses estudados no ano de 1995 e os dois anos anteriores ( Estação Meteorológica do Cabo - IPA ).

\begin{tabular}{ccccccc}
\hline Ano/Meses & Junho & Julho & Agosto & Setembro & Outubro & Novembro \\
1993 & 235.5 & 222.4 & 105.8 & 15.3 & 38.0 & 26.3 \\
1994 & 612.6 & 362.0 & 158.7 & 189.4 & 43.6 & 13.8 \\
1995 & 411.3 & 342.2 & 40.7 & 0.1 & 0.0 & 0.0 \\
\hline
\end{tabular}

Na estação I a predominância de fração areia fina ocorreu em todo o período chuvoso e no período seco dominou a fração areia média (Tab. 2).

Tabela 2 - Tamanho médio dos grãos na estação I

\begin{tabular}{lcc}
\hline 11/junho & Coletas & Tamanho Médio \\
& & valor 2.370 \\
\hline
\end{tabular}


25/junho

10/julho

31/julho

16/agosto

27/agosto

13/setembro

30/setembro

11/outubro

27/outubro

13/novembro

30/novembro classificação areia fina valor 2.035

classificação areia fina valor 2.342

classificação areia fina valor 2.140

classificação areia fina valor 2.148

classificação areia fina valor 1.704

classificação areia média valor 1.252

classificação areia média valor 1.495

classificação areia média valor 1.737

classificação areia média valor 1.711

classificação areia média valor 1.687

classificação areia média valor 1.722

classificação areia média

Plotados os perfis topográficos de modo sequencial no período chuvoso, observa-se um acréscimo de sedimento nos primeiros dias de julho, quando comparado com o perfil anterior e, posteriormente, um processo erosivo, no final do período no qual o sedimento é reposto gradativamente. No período seco os perfis topográficios mostram processos bastantes alternados de acresção e erosão, evidenciando uma erosão no início do mês de novembro (Figs.1 e 2). 


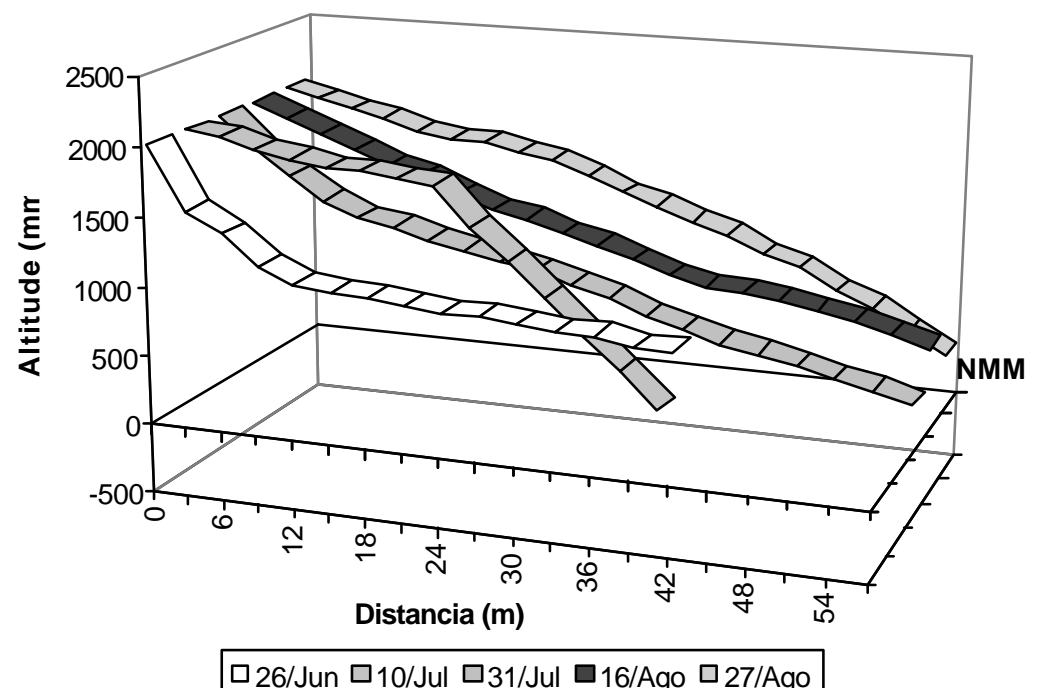

Figura 1 - Superposição de perfis na estação I no período chuvoso (nmm - nível médio da maré).

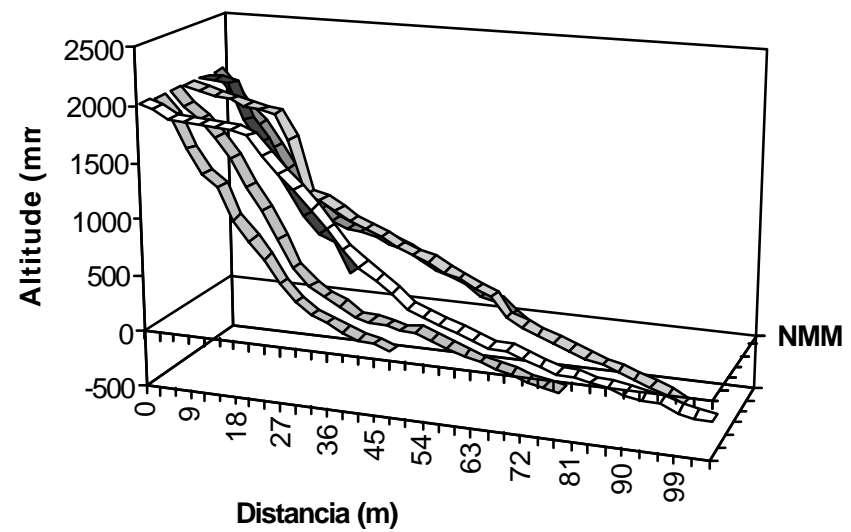

\section{$\square$ 13/Set $\square 30 /$ Set $\square 11 /$ Out $\square 27 /$ Out $\square$ 13/Nov $\square 30 /$ Nov}

Figura 2 - Superposição de perfis na estação I no período seco (nmm - nível médio da maré).

$\mathrm{Na}$ estação II o tamanho médio da fração areia variou de fina a média no período chuvoso. No período seco houve dominância de areia média com uma ocorrência de areia fina no início de novembro (Tab. 3). 
Tabela 3 - Tamanho médio dos grãos na estação II.

\begin{tabular}{|c|c|}
\hline $\begin{array}{l}\text { Coletas } \\
11 / \text { junho }\end{array}$ & $\begin{array}{l}\text { Tamanho Médio } \\
\text { valor } 2.126\end{array}$ \\
\hline & classificação areia fina \\
\hline 25/junho & $\begin{array}{l}\text { valor } 2.384 \\
\text { classificação areia fina }\end{array}$ \\
\hline 10/julho & \\
\hline 31/julho & $\begin{array}{l}\text { valor } 2.452 \\
\text { classificação areia fina }\end{array}$ \\
\hline 16/agosto & $\begin{array}{l}\text { valor } 1.804 \\
\text { classificação areia média }\end{array}$ \\
\hline 27/agosto & $\begin{array}{l}\text { valor } 1.898 \\
\text { classificação areia média }\end{array}$ \\
\hline $13 /$ setembro & $\begin{array}{l}\text { valor } 1.520 \\
\text { classificação areia média }\end{array}$ \\
\hline 30/setembro & $\begin{array}{l}\text { valor } 1.725 \\
\text { classificação areia média }\end{array}$ \\
\hline 11/outubro & $\begin{array}{l}\text { valor } 1.853 \\
\text { classificação areia média }\end{array}$ \\
\hline 27/outubro & $\begin{array}{l}\text { valor } 1.964 \\
\text { classificação areia média }\end{array}$ \\
\hline $13 /$ novembro & $\begin{array}{l}\text { valor } 2.027 \\
\text { classificação areia fina }\end{array}$ \\
\hline 30/novembro & $\begin{array}{l}\text { valor } 1.914 \\
\text { classificação areia média }\end{array}$ \\
\hline
\end{tabular}

Do início de junho até o final de agosto os perfis topográficos apresentaram processos gradativos de engordamento, ocorrendo no início de julho uma fuga de sedimento no médio litoral inferior, acarrentando um acentuado declive. $\mathrm{Na}$ fase seca as variações topográficas foram poucas, evidenciando apenas a perda de sedimentos no início de novembro como na estação anterior (Figs. 3 e 4 ). 


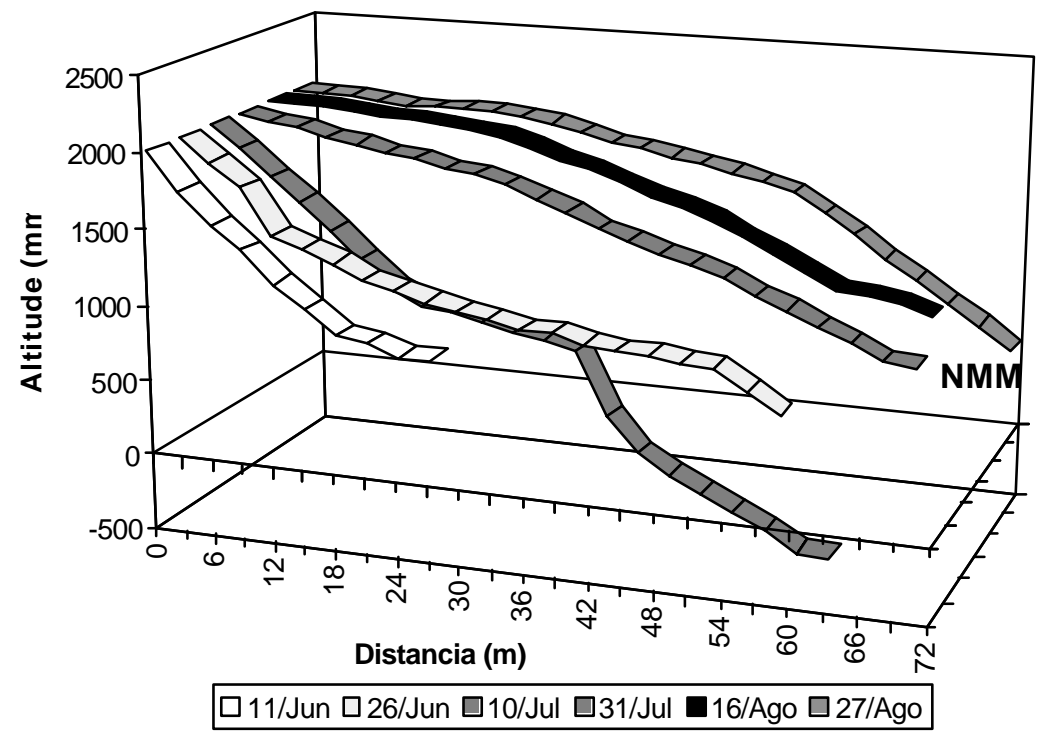

Figura 3 - Superposição de perfis na estação II no período chuvoso (nmm - nível médio da maré).

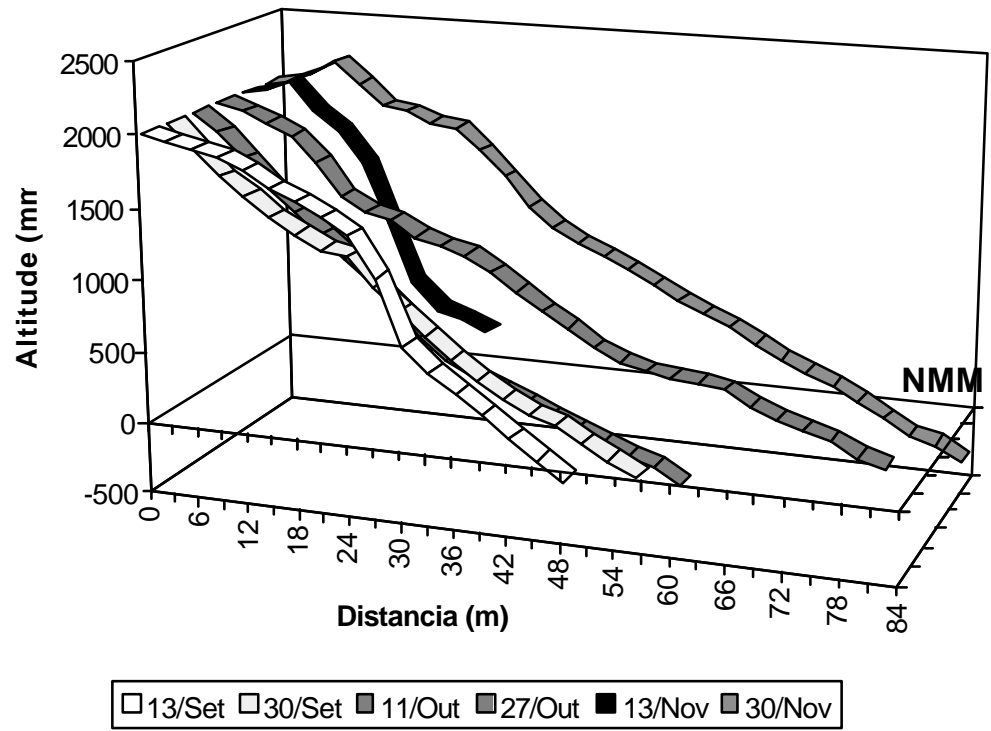

Figura 4 - Superposição de perfis na estação II no período seco (nmm - nível médio da maré). 
A meiofauna esteve composta por Turbellaria, Rotifera, Gastrotricha, Nematoda, Tardigrada, Polychaeta, Oligochaeta, Copepoda, Ostracoda, Larvas de Crustacea e Acari. B. pennaki integraram a comunidade em $28 \%$ na estação I e em $50 \%$ na estação II.

A densidade média da comunidade meiofaunística na estação I foi de 1497 ind. $10 \mathrm{~cm}^{-2}$ no período chuvoso e no período seco 2515 ind. $10 \mathrm{~cm}^{-2}$. Na estação II a densidade média no período chuvoso foi de 4274 ind. $10 \mathrm{~cm}^{-2}$ e no período seco 4644 ind. $10 \mathrm{~cm}^{-2}$. A densidade dos Tardigrada apresentou um comportamento variado entre as estações aumentando seus valores nos períodos de engordamento dos sedimentos, atingindo pico de 11.179 .2 ind. $10 \mathrm{~cm}^{-2}$ na estação II no final do mês de agosto (Fig.5 e 6). Aplicado o teste não paramétrico de Kruskal-Wallis comparou-se as amostras entre as estações $(\mathrm{H}$ crítico $=9.35)$. Houve diferença significativa quanto a densidade dos Tardigrada entre as estações $(\mathrm{H}$ calculado $=18.21$ ).

Houve correlações significativas negativas de $B$. pennaki com a média e mediana do grãos, indicando que as maiores densidades ocorrem quando há um aumento do tamanho dos grãos ( Tab. 4)

Tabela 4 - Resultados das correlações significativas dos B. pennaki com os parâmetros abióticos.

\begin{tabular}{l|l|l|ll}
\hline Taxa & \multicolumn{2}{|l|}{ Média } & \multicolumn{2}{l}{ Mediana } \\
& $\mathrm{r}$ & $\mathrm{p}$ & $\mathrm{r}$ & $\mathrm{p}$ \\
Tardigrada & - & 0.00 & - & 0.00 \\
& 0.47 & & 0.41 & \\
\hline
\end{tabular}




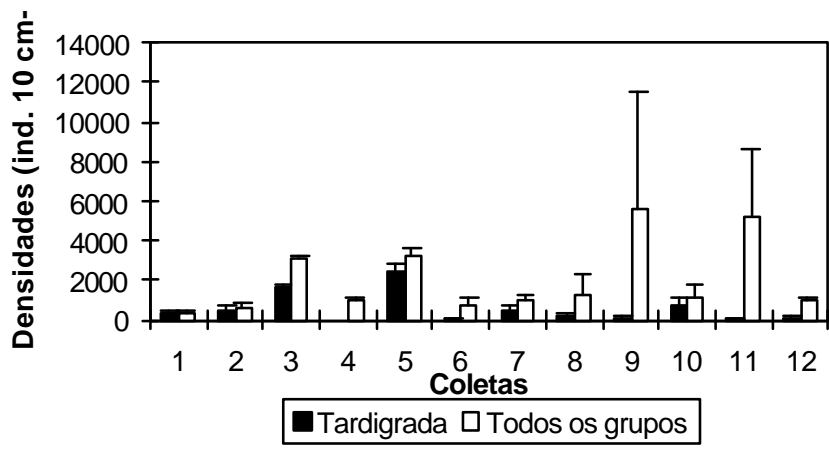

Figura 5 - Densidade Total e Desvio Padrão da Meiofauna e de Batilipes pennaki na estação I na Restinga do Paiva-PE-Brasil.

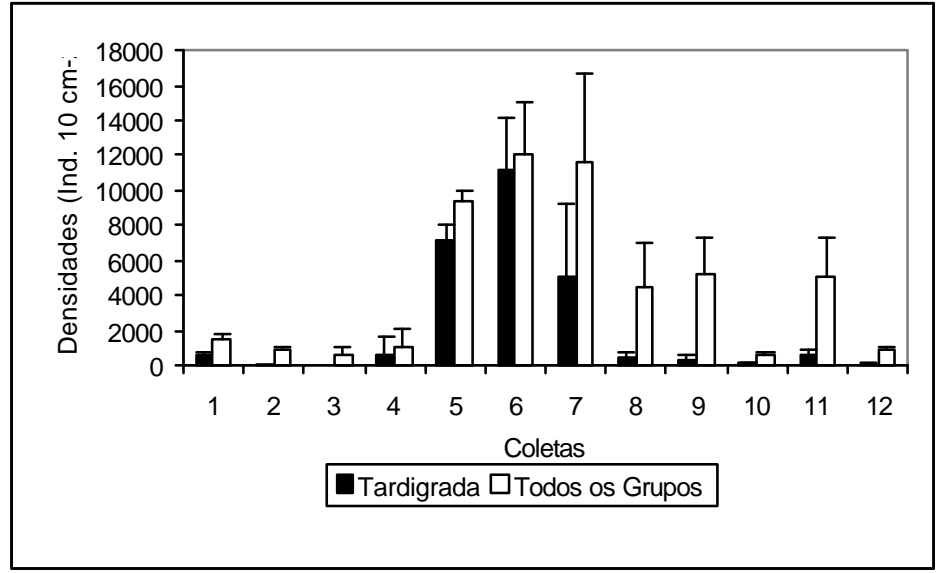

Figura 6 - Densidade Total e Desvio Padrão da Meiofauna e de Batilipes pennaki na estação II na Restinga do Paiva-PE-Brasil.

\section{DISCUSSÃO}

O índice pluviométrico ocorrido no decorrer do ano estudado mostrou que a área apresentou dois períodos bem distintos. Os dois anos anteriores 1993 e 1994 tiveram uma ocorrência de chuvas características 
ao ano estudado, porém na fase seca não foi observado mês sem pluviosidade como nos três últimos do período estudado.

A densidade média da meiofauna entre os meses dos períodos de maior e menor pluviosidade apresentou pequena amplitude de variação, sendo a máxima na estiagem. Alongi (1990) relata um drástico declínio na abundância da meiofauna após chuvas de inverno e que os efeitos dessas flutuações são maiores nos centímetros superiores. A redução das densidades meiofaunísticas no período chuvoso foi verificada em áreas tropicais típicas por Bezerra (1994) no Istmo de Olinda, por Souza (1997) no médiolitoral da baía de Tamandaré e por Silva (1997) no mesmo período ao norte da restinga, todos os tres ambientes no litoral pernambucano. Já Esteves \& Nogueira (1998) confirmam o efeito de chuvas sobre a meiofauna através de correlação existente de baixa densidades e valores baixos de temperatura e salinidade. $\mathrm{O}$ fato da maior densidade ter ocorrido no mês de agosto não exclui a restinga desse modelo, pois o referido mês apresentou baixo índice pluviométrico ( 40.7 $\mathrm{mm}$ ). Esta densidade, no entanto, reflete-se pela abundância de Tardigrada quando da máxima acresção sedimentar na área.

Fleeger e Decho (1987) afirmam que o hidrodinamismo interfere na distribuição da meiofauna seja por carrear os organismos na coluna d'água determinando sua deposição, seja por influenciar a distribuição de partículas sedimentares ou a abundância microbial.O processo erosivo ocorrido no final do mês de outubro, início de novembro carreando os sedimentos contribuem, possivelmente, para a dispersão dos Tardigrada e outros grupos da meiofauna acarretando densidades muito baixa, neste período. $\mathrm{Na}$ área oposta à restinga, ou seja, a margem esquerda deste estuário, Silva, (1997) apontou índices mais altos de densidades neste período.

$\mathrm{Na}$ estação I, cuja morfologia encontra-se estrangulada pela presença do dique de pedras, os perfis de praia revelaram que, quando a inlfuência continental é maior, ou seja, no período chuvoso, ocorre a deposição de material fino e existe um acréscimo de sedimento nesse trecho, favorecendo, como dito anteriormente, a abundância de organismos que se dispersam aderidos aos grãos, como os Tardigrada, (Giere 1993). Higgins \& Thiel (1988) comentam que várias espécies de Tardigrada conseguem sobreviver em condições adversas em um sistema hidrodinâmico praial, mudando seu habitat de acordo com as várias condições impostas pelo meio. 
Segundo LGGM (1997) em função das características das ondas, da batimetria e da orientação da praia, as frentes de ondas chegam paralelas à desembocadura do estuário, onde está localizada a estação II, formando pequenos ângulos nos trechos mais ao norte e ao sul, gerando, assim, um transporte na direção sul. Devido à sua localização, que favoreceu uma maior ação das ondas, houve carreamento de sedimentos no sentido sul. Os perfis praiais do período de maior pluviosidade mostraram que na estação II ocorreu um processo de engordamento até o final de agosto, quando foi detectado o pico de Tardigrada na comunidade. Mais uma vez evidencia-se a agregação de $B$. pennaki na comunidade meiobentônica em relação aos processos deposicionais. Este fato foi também observado por Fonsêca-Genevois et al (1992) na Coroa do Avião, ambiente transicional recente, que sofre deposições constantes (Pinto, 1996). Já Rocha (1991) havia sugerido processos semelhantes em relação a este grupo para a margem sul da ilha de Itamaracá.

Como na restinga do Paiva, na qual as correlações entre a média e a mediana dos grãos foram significativas, Rocha (op. cit.) sublinhou fato semelhante em relação à $B$. pennaki encontrando a mesma correlação na estação intermareal areno-lamosa daquela ilha, tanto para a densidade total da população quanto para os jovens. No processo de sedimentação intermareal é mais comum encontrar partículas mais finas depositadas no alto do perfil praial, no qual o tempo de emersão é fundamental para a compactação da coucha sedimentar (Gouleau, 1975).

Tal processo, aliado à temperatura, favorece ainda, a uma zonação faunal sobretudo daquela de superfície em ambientes transicionais. Fonsêca Genevois \& Ottmann (1987) definiram uma distribuição espacial da fauna intersticial e da pequena macrofauna em um perfil eurihalino do estuário do Loire, na França. Nesses sedimentos lamosos do meiodiolitoral superior havia maior densidade de organismos com desenvolvimento holobêntico, enquanto que no inferior predominavam os organismos merobênticos. No ponto intermediário ambas as formas eram encontradas detendo as maiores densidades da área. A zonação da meiofauna em zona tropical típica foi também apontada por Souza (1997) quanto a composição e dominância dos grupos em perfil de praia e por Gomes (1999) em relação aos Copepoda Harpacticoides, atribuindo a baixa densidade do grupo no alto do perfil à dessecação dos sedimentos. 


\section{CONCLUSÃO}

As correlações extraídas para $B$. pennaki na Restinga do Paiva permitiram aceitar a hipótese de que a dispersão da espécie e sua interação com a comunidade meiofaunística depende da dinâmica sedimentar, sobretudo dos processos deposicionais e erosivos em ambientes transicionais de alta energia.

\section{REFERÊNCIAS BIBLIOGRÁFICAS}

ALONGI, D. M., 1990, The Ecology of tropical soft-bottom ecosystems. Oceanography and Marine Biology, London, v 28, p. 381-496.

BENTES, A M. L. et al,. 1997, Estudo da morfodinâmica de prais compreendidas entre Saquarema e Macaé, RJ. Ecologia Brasiliensis, Rio de Janeiro. v 3, p 229 - 243.

BEZERRA, T. N. Distribuição espaç-temporal da meiofauna do Istmo de Olinda - PE, com especial referência aos Nematoda livres. Recife, 1994, 106 f. Dissertação (Mestrado em Oceanografia Biológica) - Centro de Tecnologia e Geociências., Departamento de Oceanografia, Universidade Federal de Pernambuco.

,et al 1997, Influência da granulometria na distribuição e adaptação da meiofauna na praia arenosa do Istmo de Olinda-PE. Ecologia Brasiliensis, Rio de Janeiro. v 3, p 107 - 116.

BOISSEAU, J. P., RENAUD, J. 1955, Répartion de la faune interstitielle dans un segment de plage du Bassin d'Arcachon. C. R. Acad. Sci. V. 241, p. 123 - 125.

COUTO, L. M. M. R., MELLO, R.L. S. Ciclo reprodutivo e influência da salinidade sobre a gametogênese de Ephigênia brasiliana (Lamark, 1818) (Mollusca: Bivalvia: Donacidae) no estuário da Barra das Jangadas, Jaboatão, Pernambuco. Recife. 1988, 198 p. Dissertação (Mestrado em Oceanografia) - Departamento de Oceanografia, UFPE.

et al Variação espaço-temporal da meiofauna, ao longo de um período quinzenal, em um ponto fixo da praia Vermelha, Rio de Janeiro. In IV Simpósio de Ecossistemas Brasileiros, 1998, Águas de Lindóia SP. Anais...p. 179.

ELMGREN, R. 1976, Baltic Benthos communities and the role of meiofauna. Contr. Asko Lab. Univ. of Stockholm, Sweden, n. 14 p. $1-31$. 
ESTEVES B. C. \& NOGUEIRA, C. S. R. Variação espaço-temporal da meiofauna, ao longo de um período quinzenal, em um ponto fixo da praia Vermelha, Rio de Janeiro. In IV Simpósio de Ecossistemas Brasileiros, 1998, Águas de Lindóia SP. Anais. p. 179.

FLEGER, J. W. DECHO, A W., 1987 Spatial variability of interstitial meiofauna: A review. Stygologia, v. 3, p. 35-54.

HIGGINS, R. P. \& THIEL, H. 1988 Introduction toteh Study of Meiofauna. Smithsonian Institution Press, Washington, D. C. 623 pp.

FOLK, R. C., WARD, W. C., 1957. Brajos River Bar: A study in the significance of grain size parametrs. Journal of Sedimentary Petrology. 27 (1) : 3 - 27.

FONSÊCA-GENEVOIS, V. \& OTTMANN, F. 1987, Influence de la position interdidale et des proprietés physiques des sédiments sur la méiofaune d`une vasière atlantique (Estuaire de La Loire, France). C. R. Acad. Sci., Paris, v. 304, n. 3, f. 7, p. 161-166.

FONSÊCA-GENEVOIS, V. ; INTERAMINENSE, L. J. L.; MENDES, A C. R. Meiofauna como estoque alimentício para aves limícolas na Coroa do Avião, Litoral Norte de Pernambuco. In: Encontro de Zoologia do Nordeste, 9, 1992, Recife. Resumos. Recife: Soc. Nord. de Zool., 1992, 155 p., p. 42.

FIDEM, 1987. Região Metropolitana do Recife - proteção das áreas estuarinas. Série de desenvolvimento urbano e meio ambiente. Fundação de Desenvolvimento da Região Metropolitana do Recife FIDEM. Recife. 40p.

GIERE, O 1993, Meiobenthology: The microscopic fauna in aquetic sediments. Springer-Verlag, Berlin. $328 \mathrm{p}$

GOULEAU D. T. Les premiers stades de la sédimentation sur les vasières littorales atlantiques. Rôle de l'émersion. Thèse de Doctorat ès Sciences, Université de Nantes, 123 p. 1975.

GOMES, C. A. A. Zonação da meiofauna no médiolitoral no manguezal de Itapissuma-PE, com ênfase aos Copepoda Harpacticoida. Recife, 1999, 36p. Monografia (Graduação). Univ. Fed. de Pernambuco.

GRIMALDI DE ZIO, S.; MORONE DE LUCIA,R. M.; D ADDABO GALLO,M. 1983, Marine tardigrades ecology. Oebalia, n. 9, p.15-31.

LGGM , 1997. Estudo da erosão marinha nas praias de Piedade e de Candeias e no estuário de Barra de Jangadas. Município de 
Jaboatão dos Guararapes-PE. Relatório final. Laboratório de Geologia e Geofísica Marinha, UFPE. Recife. 154 p.

LIRA, L 1994, Parecer ambiental: Estuário dos rios Jaboatão/Pirapama, impactos causados com a construção de um dique de pedra.

MEDEIROS, A. B. Compartimentações geológico-geomorfológico e geoambiental na faixa costeira sul da região metropolitana do Recife - Folha Ponte dos Carvalhos (sc.25-v-A-III/1-se) e Folha Santo Agostinho (sc. 25-v-A-III/3no). Recife: UFPE, 1996. 146 p. Dissertação. (Mestrado em Geociências) - C.T.G, 1996.

PINTO, T. K. de O. 1996. Morfodinâmica e Sedimentologia da Coroa do Avião - Barra de Orange - Itamará-PE. Trabalho de conclusão de curso (Engenharia de Pesca). Universidade Federal Rural de Pernambuco.

POLLOCK, L. W. 1970, Distribuition and dynamics of interstitial Tardigrada at Woods Hole, Massachusetts, U.S.A, Ophelia, n. 7, p. 145-165.

RAMAZOTTI, G. I. 1983,Phylum Tardigrada. Mem. Inst. Ital. Idrobil., v. 41, p. 13-1012.

RENAUD-DEBYSER, J. 1963, Récherches ecologiques sur la faune interstitielle des sables. Bassin d Arcachon, Île de Bimini, Bahamas. Vie et millieu, n. 15, p.1-157.

, SALVAT, B. 1963, Elements de properité des

biotopes des sediments meubles intertidaux et écologie de leurs populations en microfaune et macrofaune. Vie et millieu n. 14, p. 463-550.

RENAUD-MORNANT, J.; POLLOCK. L. W. A. 1971, review of the systematics and ecology of marine Tardigrada. Smithson. Contr. Zool., 76: 109-117.

RENAUD-MORNANT, J. et. al. 1984, Estimations du rôle énergetique et dynamique spatio-temporelle du méiobenthos en millien littoral: échantillonnage etmithodologie. ATP - CNRS, 982002, Rapport final, $232 \mathrm{p}$.

ROCHA, C. M. C. da. 1991, Meiofauna da margem sul da ilha de Itamaracá (PE). Com especial referência aos Tardigrada. Recife,. 260 f. Dissertação de Mestrado em Oceanografia Biológica, Centro de Tecnologia, Universidade Federal de Pernambuco.

SANTOS, P. J. P. 1999, O meiobentos da costa brasileira: padrões de diversidade, de densidade e de dominância. In: Encontro de Zoologia do Nordeste, 12, Soc. Nordest. de Zool., p. $91-100$. 
SILVA, A M. C. 1997, Relações da dinâmica costeira com a meiofauna de um ambiente impactado ( estuário do Rio Jaboatão, Pernambuco, Brasil). Recife,. 69 f. Dissertação (Mestrado em Biologia Animal) - Centro ede Ciências Biológicas, Departamento de Zoologia, Universidade Federal de Pernambuco.

SOUZA, E. M. J. 1997, Estudo da Meiofauna em uma praia da baía de Tamandaré, Pernambuco (Brasil): efeito mareal, variação temporal e dispersão. Recife,. 96 f. Dissertação (Mestrado em Biologia Animal) - Centro dede Ciências Biológicas, Departamento de Zoologia, Universidade Federal de Pernambuco. 